\title{
Venezuela: entre la Ilustración y la revolución
}

Javier Laviña

Universitat de Barcelona

España

Recibido: abril de 2014

Aprobado: agosto de 2014

Resumen: La Revolución francesa alteró las relaciones sociales en Europa dando el poder a la burguesía, clase emergente que logró cercenar los privilegios de la aristocracia. Pero al atravesar el Atlántico y recalar en las costas de Venezuela, los lemas, Libertad, Igualdad y Fraternidad alcanzaron un nuevo significado ya que alteraban el modelo productivo impuesto por los colonizadores basado en el trabajo esclavo. Para atajar el posible contagio las autoridades coloniales llevaron a cabo una política de represión que afectó tanto a seguidores de la revolución como a grupos de población sobre los que cayó la sospecha de ser partidarios del nuevo orden especialmente los pardos libres a los que vieron con nuevos ojos tanto los colonos como las autoridades.

Palabras claves: Revolución francesa, Venezuela, propaganda revolucionaria. 


\title{
Venezuela between the illustration and the revolution
}

\begin{abstract}
The French Revolution altered social relations in Europe giving the power to the bourgeoisie, the emerging class that succeeded in curtailing the privileges of the aristocracy. But once crossed the Atlantic and arrived to the coast of Venezuela, the motto, Freedom, Equality and Fraternity reached a new meaning since they altered the productive model imposed by the settlers based on slave work. To tackle the possible contagion, colonial authorities carried out a policy of repression that affected both followers of the revolution and population groups, on which fell the suspicion of being supporters of the new order, especially the free colored people, who were seen with new eyes by the settlers and the authorities.
\end{abstract}

Key words: French Revolution, Venezuela, Revolutionary propaganda.

\section{Introducción}

La influencia de la Revolución Francesa en las colonias americanas ha sido uno de los episodios que más bibliografía ha producido, sobreestimada por los estudios históricos; se ha mostrado en la historiografía europea y latinoamericana como un momento fundamental del acontecer histórico en el Nuevo Mundo. Despertó un desmesurado interés por realzar el papel de los revolucionarios, como si se tratara de incorporar América al proceso histórico occidental y que la presencia revolucionaria francesa, o afrancesada fuese un elemento fundamental de la historia de América Latina. La influencia de la revolución francesa, que naturalmente la hubo, se ha llegado ha mantener como un hecho fundamental de los procesos de independencia de las colonias americanas. Sólo Cuba, Brasil, y la República Dominicana, que alcanzaron la independencia años más tarde, ya bien entrado el siglo XIX, parecen haber estado ausentes del proceso histórico revolucionario francés. La revolución liberal burguesa pasó de largo en su momento y estas últimas colonias se incorporaron de forma tardía el proceso histórico occidental, tras la experimentación del modelo en el resto de las colonias americanas.

En Europa se estudian los efectos de la Revolución como elementos pro- 
gresivos frente a las monarquías inmovilistas; la burguesía se ha encargado mediante la utilización de la historia de presentar su ascenso al poder como positivo, lo progresista frente a las fuerzas tradicionales que representarían la negación y la regresión de los inmovilistas. La historiografía francesa ha destacado habitualmente el papel jugado por los ideólogos franceses en el proceso emancipador de las colonias hispanas, de la misma manera que los ingleses y norteamericanos han apuntado la trascendencia de sus aportaciones a los procesos de independencia latinoamericanos. $\mathrm{Y}$ es indudable que los modelos europeos inglés, francés o norteamericano fueron los que siguieron las burguesías nacionales latinoamericanas en la plasmación de sus independencias, pero fueron los criollos latinoamericanos, propietarios, en muchos casos, quienes los desarrollaron de una forma autónoma, adaptando los modelos a las realidades de sus situaciones, y lo que es más importante, a sus intereses. Pese a que las constituciones seguían los modelos liberales burgueses, y ahí podemos encontrar las influencias de los tiempos, se dieron otras propuestas alternativas a los modelos europeos que iban más allá, desde un punto de vista de organización social, propuestas que no sólo se dieron a raíz de la revolución liberal, pero que, de alguna manera, se estimularon por las protestas de grupos ilustrados o vinculados a los proyectos revolucionarios. Nos referimos a las revueltas de esclavos, el caso de la surgida en la serranía de Coro (Venezuela) en 1795, u otros de las mismas características, que fueron interpretados como consecuencia de la propaganda revolucionaria francesa, cuando en realidad sus reivindicaciones, junto a algunas cuestiones de orden económico, fin de la alcabala, o supresión del monopolio de la Compañía Guipuzcoana de Caracas, reclamaban la libertad. Los informes que se hicieron a posteriori de los acontecimientos fueron ignorando las causas económicas, resaltaron la petición de libertad, y finalmente, las autoridades coloniales interpretaron que la libertad demandada con las armas se correspondía a la libertad que proclamaban los revolucionarios franceses, de la misma manera que se interpretó que la lucha de los esclavos de Saint Domingue era por su alineamiento con las demandas jacobinas de la metrópoli. La guerra de castas se declaró de forma inequívoca. Los esclavos aprovecharon que su hora había llegado para hacerse con el poder.

Este temor a los esclavos y a la gente de color no fue exclusivo de las autoridades y criollos, de origen español, sino que afectó a los habitantes blancos de todas las colonias esclavistas. Creo que fue esto lo que se desencadenó en América una caza de brujas, como lo muestra la abundancia de material y se 
refleja en la correspondencia de autoridades. No sólo se perseguía a los agentes franceses, portadores del "virus" de la libertad, sino que se trataba de atajar el peligro que representaba la "masa de color", que siempre había planteado problemas y que por otra parte era necesaria para el funcionamiento del sistema.

Si efectivamente preocupaba la presencia de revolucionarios, más preocupaba la posibilidad de que se desatase una situación análoga a la haitiana, y esta preocupación era compartida, de igual manera, por las autoridades coloniales y por las oligarquías criollas, que cerraron filas en torno a la fe católica y a la monarquía como ejes de cohesión en las colonias. Para ello contaron con el apoyo de los tribunales inquisitoriales que, de nuevo, ofrecieron sus servicios al Estado como garantes del orden social monárquico absolutista y de los púlpitos de las iglesias desde donde se condenaba al fuego eterno a quienes intentasen alterar el orden social. La alianza iglesia, estado español, criollos, estaba servida.

\section{La propaganda revolucionaria francesa en Venezuela}

Entre los años 1789 a 1792, España mantuvo la alianza, al menos de forma teórica con Francia. Mientras la monarquía francesa no fue cuestionada, funcionó el pacto de familia firmado entre Caros III y el rey francés, por lo que el gobierno de Madrid, mantuvo una postura de neutralidad en la crisis de Saint Domingue, pero con un velado apoyo a los blancos, sin embargo el gobernador de Santo Domingo, que debía limitarse a mantener un cordón de freno frente a los revolucionarios con el establecimiento de tropas en la frontera, siguiendo el cumplimiento de las órdenes de Madrid, aprovechó el conflicto para, en primer lugar, recibir a los esclavos huidos de las plantaciones francesas y organizar algunas incursiones a la parte francesa de la isla. Con este apoyo a los esclavos huidos esperaba recuperar con la guerra la parte de la isla que España cedió a Francia el siglo anterior.

El desarrollo de la revolución y la muerte en la guillotina del rey francés cambiaron por completo las alianzas en Europa. España declaró la guerra a la Convención francesa y firmó un tratado con Inglaterra. La neutralidad se convirtió en beligerancia y del apoyo velado se pasó a integrar a una parte de los negros 
rebeldes en el ejército español. ${ }^{1}$ Con este cambio de posición por parte de los españoles la situación se hizo insostenible para los republicanos franceses que poco a poco fueron perdiendo los escasos apoyos que tenían en el campo.

La llegada al poder de Napoleón y la firma de la paz con España reactivó el interés de los franceses por el mundo colonial. Intentaron reconquistar las Antillas, en especial Saint-Domingue, destinando para tal misión al general Leclerc; pero la resistencia de los ex esclavos y el azote de la malaria hicieron fracasar su empresa. Las consecuencias de la pérdida de la colonia francesa fue un alud de emigrados, desertores y agentes revolucionarios que pulularon por el Caribe. Todos ellos, finalmente fueron sospechosos ante las autoridades coloniales españolas.

\section{Los emigrados}

Los triunfos de los esclavos en armas y las tensiones entre los pobladores blancos de la colonia provocaron la salida masiva de blancos de la parte francesa de la isla, estos refugiados se dirigieron hacia distintas colonias europeas donde esperar a que la situación se resolviera de forma favorable a sus intereses. No se puede decir que se tratase de un exilio, ya que podían volver a la colonia y mantener sus propiedades cuando quisieran; sin embargo los acontecimientos hicieron que lo que en principio había sido refugio se convirtiera, en muchos casos, en residencia definitiva de los colonos franceses. En un primer momento, los emigrados se dirigieron hacia zonas próximas a las Antillas, en lo que ellos consideraban un paréntesis de espera. Un grupo considerable se trasladó a la colonia española de Santo Domingo, Un segundo grupo se dirigió a Jamaica, con la esperanza de que los ingleses tomaran la colonia de Saint-Domingue. Tras un breve paréntesis en estos primeros territorios, algunos de los ya exilados, se trasladaron finalmente a Cuba, donde fijaron su residencia definitiva e impulsaron los cultivos tanto del

1 Para ver el papel de los ex esclavos en el ejército español durante el periodo de la guerra de independencia de Haití ver: Jorge Victoria Ojeda, "La aventura imperial de España en la revolución haitiana. Impulso y dispersión de los negros auxiliares: el caso de San Fernando Aké, Yucatán", en Secuencia n. ${ }^{\circ}$ 49, México, Instituto Mora, 2001, pp.70-85; y "Tras los sueños de libertad: las tropas auxiliares de Jean François al fin de la guerra en Santo Domingo, 1793-1795", en S. Broseta, C. Corona, M. Chust, et al (eds.), Las ciudades y la guerra, 1750-1898, Castellón, Universitat Jaume I, 2002, pp.509-524. 
azúcar como del café. ${ }^{2}$ Finalmente, hubo otro grupo que decidió retirarse hacia los Estados Unidos donde fijaron definitivamente su residencia.

\section{Los desertores}

En 1790, Francia envió tropas a las colonias para hacer respetar el pacto colonial. En principio, los plantadores y colonos vieron en los refuerzos militares la salvación de sus propiedades, amenazadas por los grupos más radicales, En general, los oficiales y marinos de refuerzo eran fieles a la Corona, y se opusieron tanto a los intentos autonomistas de los colonos como a los revolucionarios. Pero la represión llevada a cabo por el ejército francés no solucionó los problemas de las Antillas, y en enero de 1793 el conde de Riviere, jefe de división de las islas de Sotavento, y Fressineaux, comandante del regimiento Mariscal de Turena, tuvieron que retirarse precipitadamente de las islas porque los jacobinos habían amenazado con hundir la flota si no se les unían.

Los colonos de Martinica, donde los ecos de la revolución también se dejaron sentir, no aceptaban la presencia realista porque pretendían conseguir su autogobierno, decidieron apoyar a los jacobinos, y forzaron la retirada de las tropas fieles a la Corona. ${ }^{3}$

Los oficiales realistas del ejército francés huyeron hacia Trinidad, Buscando la protección de la Corona española; para ellos el monarca español era, ante todo, un Borbón, y según ellos el pacto de familia firmado en 1762 seguía vigente. Estos militares fueron bien recibidos por las autoridades militares con mando directo, ya que ofrecían un buen conocimiento de la situación en las colonias galas, necesario para el desarrollo de la guerra colonial. La corona aceptó el juramento de fidelidad al rey que hicieron los franceses, y los incorporó al ejército español con las mismas graduaciones que tenían en el francés. En este punto surgieron las primeras discrepancias con las autoridades coloniales, que no

2 Véase Gabriel Debiens, "Les colons de Saint Domingue réfugiés a Cuba (1793-1815)", en Revista de Indias vol.XIII, n. ${ }^{\circ}$ 54, Sevilla, EEHA, 1953, pp.559-605, y Revista de Indias vol.XIV, n. ${ }^{\circ} 55^{-56}$, Sevilla, EEHA, 1954, pp.11-36.

3 Ver Jules Santoiyant, La colonisation française pendant le Révolution (1789-1799), Paris, La Renaissance du Livre, 1930. 
estaban de acuerdo con la equiparación de graduaciones. Riviére, jefe de la armada, ofreció a Gabriel de Aristizabal, capitán general de la escuadra española, la posibilidad de formar dos cuerpos de ejército: uno de marina, a su mando, y un cuerpo de tierra al mando de Fressineaux. Aristizabal creyó conveniente reunir a todos los realistas emigrados y a los desertores del ejército francés bajo el mando de sus dos jefes militares y enviarles a la frontera de Santo Domingo donde se había abierto un frente. ${ }^{4}$ La propuesta no fue aceptada por el gobernador de santo Domingo, que contaba entre sus tropas a varios de los líderes negros en lucha contra los franceses, y consideraba más importante esta alianza que la de los oficiales realistas. De hecho, los españoles habían comenzado una ofensiva sobre la parte francesa de la isla y habían recuperado algunos territorios.

Para resolver la situación planteada en Saint-Domingue, el delegado de la Convención en la colonia francesa decretó la libertad de los esclavos en el norte de la isla, mientras Polvérel hacía lo mismo en el oeste y en el sur. Esta medida fue realmente efectiva, pues los esclavos liberados formaron parte del ejército que se opuso a españoles e ingleses. Toussaint Louverture, que había sido nombrado general del ejército español, se pasó a las filas francesas y la guerra cambió su rumbo en Santo Domingo. ${ }^{5}$

Pese a la buena acogida inicial de los oficiales realistas, se ordenó su traslado a Caracas en espera de un destino definitivo, Sin embargo, el nuevo destino parecía no llegar, y Fressineaux envió una carta al Capitán General de Caracas en la que se quejaba de la inactividad a la que se les tenía sometidos por lo que pedían se les destinase o a otra plaza de América o a España y combatir la revolucionen Europa. Los motivos de tal inacción eran en primer lugar la falta de dinero, problema secular de la Real Hacienda, que no podía asumir un gasto extraordinario como el que representaba pagar los servicios de los militares franceses, en segundo lugar la fiebre contrarrevolucionaria que afectó a las autoridades coloniales, que les llevaba a ver graves peligros en todo lo francés fueran del signo que fueran, y los oficiales realistas no estuvieron libres de sospecha; este delirio contrarrevolucionario afectó, especialmente, al Capitán

\footnotetext{
4 Archivo General de Indias (AGI) Sección Estado, Legajo 58. Carta de Gabriel de Aristizábal al Capitán General de Caracas. Puerto Cabello 14 de Octubre de 1793.

5 Ángel Sanz Tapia, Los militares emigrados y los prisioneros franceses en Venezuela durante la guerra contra la revolución: (un aspecto fundamental de la época de la preemancipación), Caracas, Instituto Panamericano de Geografía e Historia, 1977, pp.69-70.
} 
General de Caracas, que en toda su actuación procuró cubrir su responsabilidad de gobierno con "exceso de celo": los militares franceses fueron acusados de "presentarse en los templos con aire y gestiones irreligiosas, volviendo la espalda a los altares aun cuando se celebra el Sacrosanto Sacrificio, ocupando ese tiempo en observar las facciones de las mujeres; y ocasionando las distracciones, mala nota y ejemplo que son consiguientes", ${ }^{6}$ así como también se les acusó de mantener conversaciones peligrosas para el orden colonial. Ciertamente, la inactividad y los retrasos en el cobro de los haberes había provocado malestar entre los oficiales, y se dieron algunos casos de insubordinación. Otra de las acusaciones fue la de haber propagado máximas revolucionarias. Ese celo llegó al extremo de ordenar Carbonell a Fressineaux "inmediatamente a la venida de los emigrados franceses se esparcieron por la ciudad monedas de plata con inscripciones alusivas a la libertad y la nueva constitución de la Francia".7

Lo cierto era que los militares realistas del ejército francés resultaban molestos al Capitán General de Caracas, y desde su llegada trató de enviarlos fuera de su jurisdicción, poniendo trabas a todas las posibles soluciones a la problemática que planteaban. En primer lugar argumentó la imposibilidad de ocuparles, y por tanto era mejor que se refugiasen en Santo Domingo; ante las sugerencias de Aristizabal y las órdenes de la Corona accedió a que los realistas franceses permaneciesen en la Capitanía; pero les sometió, observando la Real Orden, a una estricta vigilancia por ser sospechosos de introducir objetos alusivos a la revolución; y finalmente les acusó de irreligiosidad, y en consecuencia de filo revolucionarios.

Las propuestas del Capitán General de Caracas para que los emigrados y desertores franceses saliesen de la Capitanía fueron rechazadas por Aristizabal. Carbonell proponía que la armada trasladase a los franceses a cualquier otro lugar del Caribe, o incluso a España; Aristizabal se opuso porque decía no poder destinar ninguna embarcación al transporte de franceses, exponiéndola a ser capturada, y dejando las costas venezolanas poco protegidas. Por otra parte, la salida de Venezuela de los desertores y emigrados sería para instalarse en

6 AGI, Sec. Estado, leg.58. Informe de la Junta de Caracas, 4 de noviembre de 1793.

7 AGI, Sec. Estado, leg.58. Informe de la Junta de Caracas, 4 de noviembre de 1793. 
cualquier otro puerto, con lo que el "peligro" se mantenía en las colonias. ${ }^{8}$

El problema comenzó a resolverse a partir de las medidas drásticas que de palabra trasmitió Carbonell a Fressineaux; le comunicó la obligación de todos los oficiales y sargentos emigrados de presentarse en el puerto de La Guaira en un plazo de 48 horas para incorporarse a las tropas de Aristizabal; quedarían excluidos todos aquellos que solicitasen pasaporte para Trinidad o cualquier otra colonia extranjera. Carbonell escribió a Aristizabal y al Gobernador de Puerto Cabello, comunicándoles la decisión adoptada; al primero le indicaba que los oficiales debían ser embarcados, y que en caso contrario habían de ser entregados a cargo del gobernador de Puerto Cabello; y a éste le ordenaba que se responsabilizara de los oficiales y que solicitase dinero al Intendente para hacerse cargo de los gastos que ocasionasen. La solución final llegó de la corte. Una real orden indicaba a Carbonell que, recogiendo las peticiones de la Junta de Caracas y viendo la imposibilidad de ocupar a los emigrados en los frentes antillanos (recordemos que el gobernador de Santo Domingo se oponía a la presencia de tropas realistas francesas en la parte española de la isla), se ocuparía a los oficiales en Europa. Carbonell reunió a los realistas franceses en la Guaira y los expidió para Cádiz en distintas fechas. ${ }^{9}$ Si los emigrados y militares franceses suponían un problema para el Capitán general de Caracas mayores quebraderos de cabeza eran los prisioneros que se capturaban en Santo Domingo.

\section{Los negros y prisioneros}

La guerra contra Francia en las colonias se saldó, al menos durante los primeros meses, de forma favorable para ejército colonial español. La colaboración de los esclavos de Saint-Domingue y su incorporación al ejército ofrecieron algunos triunfos al Gobernador de Santo Domingo, que llegó a ocupar algunos territorios de la parte francesa de la isla. Los triunfos se tradujeron en un considerable número de prisioneros y negros franceses que no podían ser retenidos en la parte

8 AGI, Sec. Estado, leg.58. Carta de Gabriel de Aristizábal al Capitán General de Caracas, Puerto Cabello 6 de noviembre de 1793.

9 A. Sanz Tapia, Los militares emigrados y los prisioneros franceses en Venezuela, pp.185257. 
española de la isla por falta de seguridad. El gobernador temía que la presencia francesa en la isla pudiera provocar un desastre parecido al que sufría Saint Domingue. Desde la proclamación de la República en Francia, en las colonias se temía por la seguridad, y se habían tomado medidas especiales para el control de extranjeros. Naturalmente, los elementos más peligrosos eran los soldados del ejército francés, todos revolucionarios y adictos a la República; con estos antecedentes era fácil comprender que ningún gobernador de las colonias estuviese tranquilo con los prisioneros en su territorio. El gobernador de Santo Domingo tenía un fácil pretexto para expulsar a los franceses de su gobernación: la guerra. Los problemas, reales o ficticios, que pudieran causar los franceses en las colonias americanas eran tenidos en cuenta por el Capitán General de Santo Domingo, que proponía que, pese a que los prisioneros fueran remitidos a Puerto Cabello, se reexpidiesen luego a la Habana o a España para mayor seguridad. ${ }^{10}$

Las circunstancias de la guerra impidieron el traslado de los prisioneros de las cárceles de Venezuela, pese a las reiteradas protestas tanto de Pedro Carbonell, Capitán General de Caracas, como de la Junta de Caracas, y tras un primer envío de prisioneros siguieron varios más, que causaron las airadas protestas de Carbonell ante los graves problemas que planteaba la presencia francesa en la Capitanía de Venezuela. El gobernador de Santo Domingo excusaba el envío de prisioneros hacia Puerto Cabello por la difícil situación que atravesaba la isla, y por los problemas relacionados con la propaganda revolucionaria que podían causar los prisioneros en esa zona. A la situación de guerra había que añadir la falta de recursos de las Cajas Reales, motivo por el que, según Joaquín García, Capitán General de Santo Domingo, se veía éste en la obligación de enviar a los prisioneros a Venezuela. Hay que aclarar que el gobernador de la isla distinguía entre los prisioneros dos grupos: los patriotas, causa de todos los desórdenes revolucionarios, y los negros. Los patriotas procedían de los cuerpos expedicionarios de la metrópoli, y se les consideraba como los propagandistas de la revolución; los negros, pese a que fueron, en definitiva, los que hicieron la revolución y consiguieron la independencia, no eran considerados peligrosos por el Capitán General de Santo Domingo, y en el envío de prisioneros que hace a Venezuela propone que fuesen vendidos como esclavos: "Los negros hiran

10 AGI, Sec. Estado, leg.58. Carta del Gobernador de Santo Domingo al Capitán General de Caracas, Santo Domingo 16 de agosto de 1793. 
relacionados deberan venderse por cuenta de la Real Hacienda en esa capital cuio producto estara en caxas a buena cuenta del prestamo que hicieron a virtud de mi petición".11

La actitud del Capitán General de Santo Domingo es comprensible, habida cuenta que en el ejército español había un cuerpo de ex-esclavos de Saint-Domingue que lucharon contra los franceses en la isla. Sin embargo la tolerancia de Joaquín García hacia los negros no compartida por Carbonell, que veía en los negros franceses el mayor peligro para la seguridad de la Capitanía de Venezuela, puesto que pretenderían la abolición de la esclavitud y el fin del orden colonial en América. Naturalmente, el Capitán General de Venezuela se negó a que los negros fuesen vendidos en la Capitanía, y suponía que "[...] no habrá en todas estas provincias quien compre ni aún reciba de balde en su casa algunos de los tales esclavos; porque nadie querrá introducir en su familia un seductor pernicioso embebido de las máximas de insubordinación y libertad”. ${ }^{12}$

Al margen de la afirmación de la Junta, que presuponía ya el comportamiento de los hacendados, reconoce que los más hacendados no permitirían que nadie importase esos negros por el riesgo que correría la Provincia en general, que ya con taba según los cálculos de la Junta con 100.000 esclavos y con más de 200.000 libertos, negros y de color quebrado. En este informe se aprecia y aparece el verdadero temor de los notables de Caracas: el miedo a la pardocracia, capaz de organizarse políticamente en torno a la igualdad propugnada por la Revolución Francesa. Sin embargo este temor aparece también cuando la Corona dicta la "Real Cédula de Gracia al sacar", según la cual los pardos enriquecidos podían comprar la limpieza de sangre a cambio de un canon estipulado. No es pues la ideología revolucionaria lo que preocupa a la Junta, sino la lucha por la igualdad y la posibilidad de que los pardos llegasen a conseguir puestos de gobierno que les estaban vedados. Y pensamos que los temores de Carbonell y la Junta de Caracas no eran infundados, ya que efectivamente había cierta proclividad por parte de los grupos de color hacia la igualdad con los blancos; pero esta situación no necesitaba del influjo revolucionario francés para desarrollarse. De hecho, la Revolución podía hacer fracasar las aspiraciones de los pardos enriquecidos, que eran los únicos que querían llegar a conseguir la

11 AGI, Sec. Estado, leg. 58. Carta del Gobernador de Santo Domingo al Capitán General de Caracas, Santo Domingo 19 de octubre de 1793.

12 AGI, Sec. Estado, leg.58. Informe de la Junta de Caracas 9 de noviembre de 1793. 
igualdad con los blancos pero en ningún momento estaban dispuestos a compartir la igualdad con los grupos populares.

La influencia de los prisioneros y negros franceses se hizo sentir, según las autoridades caraqueñas, en los grupos menos favorecidos de la sociedad; de hecho estos grupos habían ofrecido resistencia activa al dominio de los criollos, y se habían enfrentado abiertamente a la sociedad creada en complicidad por la metrópoli y los criollos, sin necesidad de recurrir a las consignas de los revolucionarios franceses; si bien es cierto que las repercusiones de la revolución en Haití abrieron una brecha en el bloque monolítico de las sociedades esclavistas americanas, debe entenderse que no se trató de una influencia ideológica sino de un estímulo puntual frente a la inercia de la sociedad colonial. El equívoco proviene de la utilización por parte de los grupos marginales de la palabra "libertad", que los criollos "afrancesaron".

Las repercusiones de la presencia francesa en la Capitanía de Venezuela se tradujeron tan sólo en conversaciones y rumores detectados por las autoridades coloniales entre la población de color, libre y esclava, y entre los presidiarios de la Guaira. La Junta de Caracas encargó a sus miembros una investigación para “[...] conocer el verdadero estado de las opiniones insinuadas entre los esclavos y gente libre de color quebrado". ${ }^{13}$ Sin embargo en las juntas celebradas a lo largo del mes de noviembre no aparece ninguna referencia concreta a actividades revolucionarias de la población de color, pero se repiten las quejas respecto al peligro que supone para la colonia la presencia de los franceses en la Capitanía, y solicitan del Capitán General de la Armada la cesión de embarcaciones para el traslado de todos los franceses a presidios más seguros. Las únicas referencias concretas a la influencia revolucionaria entre la población de color libre y esclava de Venezuela aparece en la junta del 2 de noviembre de 1793, y se refiere a conversaciones que algunos informadores habían oído a los negros. ${ }^{14}$

La solución a tan grave problema debía resultar de la colaboración de todos los grupos de poder establecidos en la Capitanía, y, especialmente, se requería la ayuda del comandante de la Armada para que no transportase más franceses a Venezuela y se llevase a los que estaban depositados en la Guaira.

13 AGI, Sec. Estado, Informe de la Junta de Caracas de 2 de noviembre de 1793.

14 AGI, Sec. Estado, Informe de la Junta de Caracas de 2 de noviembre de 1793. 
Parece ser que existía una cierta tensión entre el máximo representante de la Corona y los funcionarios de nuevo cuño (fundamentalmente con el intendente, que controlaba la hacienda del ejército). Esta división de poderes dentro de la administración causó no pocas tensiones entre los distintos estamentos del gobierno colonial, pues los capitanes generales no podían disponer libremente del ejército ya que debían contar con la aprobación del intendente para realizar cualquier movimiento de tropas; estas situaciones hicieron que en muchos casos los gobernadores aportasen dinero de sus cajas y posteriormente reclamaran a la Corona su intervención para recuperar los fondos, o bien se recurría a las milicias que eran mantenidas por los vecinos que reclamaban su intervención ante los conflictos; esta es una de las razones por la que en todos los informes se recalcaba la necesidad de "estado" y el peligro que suponían los alzamientos, no sólo para la tranquilidad pública, dependiente del gobierno, sino para la continuidad de la colonia como tal. En los cuatro casos prácticos que presentamos como ejemplos de sublevaciones populares en los territorios dependientes del Virreinato de Nueva Granada se repiten hasta la saciedad los peligros que representaron la seguridad y la continuidad de la colonia. En todos ellos los delegados de intendencia tuvieron que autorizar y asumir los gastos generados en la represión de los levantamientos.

En este contexto de recuperación y lucha por las funciones administrativas hay que entender los desacuerdos del Capitán General de Caracas y el Capitán General de la Armada sobre el traslado de los prisioneros y emigrados a otras áreas de América, y el interés de Pedro Carbonell en presentar la influencia, que siempre fue muy limitada, de los revolucionarios franceses como el mayor peligro para el sistema colonial.

Iguales peligros se padecerían remitiendo esta gente a la plaza de Cartagena, que aunque fuerte, no tiene proporciones para mantener los prisioneros con la necesaria separación del pueblo; [...] desde la cual como de estas costas pueden difundirse sin mayor dificultad a toda nuestra América Meridional las insinuadas opciones y renovar sus movimientos sediciosos los malignos que ahora están contenidos o prófugos. En consecuencia, es el dictamen uniforme de la junta que el Sr. intendente se sirva mandar fletar los barcos necesarios (para que) los conduzca y proteja hasta la Havana. ${ }^{15}$

15 AGI, Sec. Estado, Informe de la Junta de Caracas 9 de noviembre de 1793. 
Pese a los deseos de la junta, el intendente se excusó con varias razones, y no permitió la utilización de los barcos de la Armada para el traslado de prisioneros y emigrados. En el mismo mes de noviembre, la junta de Caracas recibió la petición de ayuda por parte del Capitán General de Santo Domingo para hacer frente a los franceses; en principio se pensó en enviarles a los refugiados y emigrados, pero finalmente se accedió a conceder la ayuda que reclamaba. Pese a todo, los caraqueños seguían protestando por la llegada de nuevos prisioneros a sus territorios, y se plantearon la posibilidad de devolverlos, o al menos no dejarles desembarcar. Sin embargo, ante las presiones y razones del Capitán General de la Armada, tuvieron que ceder, y recibieron en la cárcel de la Guaira a cerca de 600 prisioneros. Pese a la insistencia por parte de la junta de Caracas en el peligro que suponía para

estos países y toda la tierra firme las execrables y contagiosas opiniones que han pervertido y arruinado la Francia y sus colonias, trastornando todo el orden social, los vínculos y fundamentos más sagrados de la religión y del estado, constando como consta que los indicados prisioneros siguen la perjudicial doctrina del sistema de los regicidas franceses. Su desarreglada libertad e igualdad y también que algunos abrazan el plan de irreligión y persiguen el templo y el altar con el criminal empeño de difundir tan detestables ideas. ${ }^{16}$

No hay un sólo dato excepto los dos casos algo difusos presentados en la junta del día dos de noviembre, que nos permita pensar en una posible influencia de los revolucionarios franceses en la Capitanía de Venezuela; solo aparece alguna referencia a la influencia francesa directa en la sublevación de Gual Picornell y España de 1797, que se dice estuvo inspirada por el ejemplo de los prisioneros franceses.

16 AGI, Sec. Estado, Informe de la Junta de Caracas 13 de noviembre de 1793. 


\section{Los agentes revolucionarios}

Las relaciones entre las monarquías europeas y la Francia de los Estados Generales se vieron alteradas por el temor de Europa a las repercusiones que pudieran tener en cada país los acontecimientos franceses. Las monarquías, que habían aceptado de buen grado la Ilustración y habían iniciado en muchos casos la modernización del Estado de acuerdo con las nuevas corrientes, comenzaron a poner trabas a todo lo procedente de aquel país, al mismo tiempo que en todos los reinos se pusieron impedimentos a los ciudadanos franceses que querían cruzar las fronteras para evitar la entrada de agentes revolucionarios.

En el caso de España, las medidas adoptadas en la metrópoli se aplicaron también en las colonias, decretándose una serie de leyes para impedir el paso de la revolución a los territorios americanos. El nuevo continente había tenido pocos años antes, en 1776, un ejemplo de lucha anticolonialista en la independencia de las Trece Colonias y la propaganda francesa podía ser un nuevo aliciente entre los colonos para reclamar la autonomía política absoluta.

La principal preocupación que tenían las autoridades coloniales, más que referente a los agentes revolucionarios o las gacetas y panfletos que pudieran llegar de Francia, hacía hincapié en los residentes extranjeros, susceptibles de ser receptores de la propaganda revolucionaria y crear un estado de opinión contrario a la monarquía. Pese a que las Leyes de Indias eran tajantes al respecto y prohibían la residencia de extranjeros en América, lo cierto es que había una colonia internacional importante; su estancia en América podía incluso ser legal, y podían estar registrados o afincados sin cumplir ningún requisito. El control de extranjeros había sido siempre una obsesión de la política migratoria. Durante los primeros años, los reyes trataban de velar por la pureza religiosa en el Nuevo Continente. Cuando la competencia europea se lanzó sobre América, la corona trató de impedir el paso de extranjeros que pudieran ser agentes de otras metrópolis. Sin embargo la realidad comercial hispano-americana hacía imprescindibles a los extranjeros, que actuaban como agentes comerciales y cubrían las áreas que los españoles no podían abarcar.

La Capitanía General de Venezuela, por su proximidad a las islas francesas, inglesas y holandesas, fue un buen lugar para el establecimiento de ciudadanos de estas nacionalidades, que se dedicaban al comercio o bien ejercían profesiones 
liberales. Durante la década de los 80, los gobernadores dieron órdenes a los tenientes de justicia para que controlasen a los extranjeros de conducta sospechosa. Ante los acontecimientos de Francia, el Capitán General de Caracas decidió expulsar, para evitar la introducción de propaganda, a todos los extranjeros.

El cumplimiento de la orden se dejó en manos de los tenientes de justicia, quienes no siempre actuaron de forma acertada: "[...] al justicia de San Sebastián (Venezuela) se le amonestó a que limitase sus averiguaciones a los extranjeros y no a los vizcaínos a quienes había incluido en la común ignorancia de no creerlos españoles". Una situación similar se dio en la villa de Cura, de donde el Capitán General recibió quejas elevadas por los vecinos canarios que eran investigados por el teniente de justicia. ${ }^{17}$

Tras la muerte de Luis XVI y la declaración de guerra entre España y Francia, en 1793, las sospechas contra los franceses arreciaron, y se decidió arrestar a cualquier persona que mostrase simpatía o creyese favorable el sistema francés. Todos los gobernadores dependientes del Virrey de Santa Fe tenían que informar sobre los extranjeros "[...] que residan en su distrito, tiempo, modo con que vinieron a él, edad, estado ejercicio y conducta según los informes que de ella tenga". ${ }^{18}$ Se intentaba tener un conocimiento exacto de la colonia extranjera, y especialmente controlar a los franceses: en la misma instrucción se ordenaba la expulsión de todos los ciudadanos franceses considerados "nocivos". La vigilancia de estos ciudadanos fue bastante efectiva, pero propició la "caza de brujas".

La conclusión que se puede obtener, vistos los casos de revolucionarios extranjeros, es que los adictos al nuevo sistema eran escasos, y que, excepto sentimientos de alegría por la situación alcanzada en Francia o conversaciones sobre los progresos de los franceses, no hubo ninguna otra alteración de la normalidad. Las acusaciones que se hacían a los encausados eran absolutamente imprecisas; en abril de 1792 se detuvo a un simpatizante de la revolución, y fue

17 William Callahan, "La propaganda, la sedición y la Revolución Francesa en la Capitanía General de Venezuela de 1789-1796", en Boletín Histórico n. ${ }^{\circ}$, Caracas, Fundación Boulton, 1967, pp.180 y ss.

18 AGI, Sec Estado, leg.53. Instrucción reservada a todos los gobernadores delas provincias de este virreinato conforme a las reales órdenes comunicadas al virrey. Santa Fe 15 de septiembre de 1795. 
enviado a España; en principio se pensó que era un italiano, pero era español y se llamaba Fernando Ribas; se le acusó de haber mantenido conversaciones sediciosas y de haber "viajado a Europa y en ambas Américas" por lo que el Capitán General consideró que era un elemento peligroso y desestabilizador. ${ }^{19}$

La ejecución del rey francés y la declaración de guerra a la Convención, desataron aún más los temores ante la influencia revolucionaria francesa, y en enero de 1793 se detuvo a Guanare a un médico galo que, según dijeron, había celebrado el regicidio. Carlos IV incluyó en la real Cédula de 1795 una orden especial para todos los Justicias Mayores de la Capitanía de Venezuela en la que se ordenaba que tuviesen "[...] el mayor celo y vigilancia en la más exacta observancia de lo prevenido en las leyes de esos dominios contra los extranjeros, y especialmente los de la Nación Francesa que sin carta de naturaleza ni mi licencia real se hallan en ellos o se hiciesen sospechosos en su conducta, operaciones, conversaciones peligrosas o seductivas de esos mis fieles vasallos”. ${ }^{20}$

Otras dos personas cayeron bajo la acusación de revolucionarlos; se trataba de Francisco Combret, estanquero de la renta del tabaco de Maracay, de origen francés, y Santiago Alví, comerciante de San Sebastián. El primero había hecho en público comentarios favorables a la Convención de París, mientras que el donostiarra, según la Audiencia de Caracas, había celebrado la ocupación de San Sebastián por los franceses, y había dicho que se negaría a prestar auxilio a los españoles si los franceses decidían invadir la Capitanía. Recordemos que se dieron algunas muestras de alegría, que se patentizaron en lanzamientos de petardos, celebrando los avances franceses en la guerra de España; pero no pudieron localizar a los culpables.

Las repercusiones de la Revolución Francesas en Venezuela se limitaron a estos hechos y personas, al margen de algunos bulos que se extendieron sobre la presencia de agentes revolucionarios que no estuvieron presentes sino en los rumores sobre su presencia. En cuanto a los acusados, se les confiscaron los bienes, que se cedieron a la Real Hacienda. En Puerto Cabello se produjo la detención de un capitán de la marina procedente de Curaçao que tenía noticias de la huída del rey de Holanda ante el avance francés; los bulos que recorrían las mentes de todo tipo de funcionarios, aumentaban ante la presencia de

19 W. Callahan, "La propaganda, la sedición y la Revolución Francesa”, p.181.

20 AGI, Sec. Estado, leg.50. Real cédula, Aranjuez 23 de marzo de 1795. 
embarcaciones extranjeras frente a la costa. En parte, estos rumores aumentaban a causa de las dificultades de comunicación entre España y sus colonias, y eran potenciados por el miedo de los criollos a perder el poder político y económico que mantenían dentro de la Capitanía. Pese a las escasas muestras de fervor revolucionario afrancesado, las autoridades coloniales y la Junta de Caracas se empecinaron en ofrecer la imagen de una Capitanía en la que pronto se produciría la liberación, por la influencia de presos, emigrados y agentes franceses. Pero la poca resolución de la Corona ante las protestas, quejas y miedos de los caraqueños nos hace pensar que la metrópoli se tenía una idea más real sobre la situación y el peligro hipotético que pudieran causar de hecho los efectos de la Revolución. Sin embargo, es cierto que entre los profesionales liberales y algunos elementos extranjeros se dieron ciertas simpatías, pero no pasaron de conversaciones de rebotica o de alguna muestra de alegría, que bien podía ser debida a causas absolutamente ajenas a la marcha de la guerra en España o a los triunfos de la Revolución en el escenario europeo.

\section{El control de la pardocracia}

Uno de los grupos que más padeció persecución por la psicosis antirrevolucionaria desatada en la Capitanía de Venezuela fue el formado por los pardos. A este segmento heterogéneo de la sociedad se le acusaba de intentar alcanzar la igualdad de derechos con los blancos. Los pardos formaban el grupo más ecléctico de los que conformaban la sociedad venezolana; existía una cierta solidaridad dentro del grupo de los blancos, e incluso los de condición social menos favorecida se sentían solidarios de los grandes propietarios, ya que en principio no tenían limitaciones en los usos sociales de la colonia. Entre los privilegios de que gozaban los pertenecientes a los grupos procedentes del viejo continente figuraba el poder llevar armas, vestir a la europea, ocupar cargos de gobierno, y ocupar determinados lugares dentro de la iglesia. Junto a estos privilegios sociales, los blancos recién llegados esperaban mejorar su situación económica por vía matrimonial; la situación social de este grupo no era pues, nada infausta si tenemos en cuenta los puestos a los que sus integrantes podían aspirar. Por el contrario, los mulatos, catalogados genéricamente como "pardos", pese a que podían ser propietarios y de una situación económica desahogada, estaban 
socialmente discriminados por el color de su piel, delator del dudoso y posiblemente pecaminoso cruce que les había "blanqueado". Los pardos estaban excluidos de los organismos de gobierno coloniales, como los cabildos, o la audiencia; además, de tanta trascendencia como las limitaciones políticas eran las restricciones sociales a las que estaban sometidos, tales como la prohibición de usar oro, prendas de seda, o llevar espada. El control de los mestizo se llevaba a cabo en las parroquias, en las que los curas cumplimentaban el "libro de pardos" en los que se anotaban los bautizos de gentes de color. También otras instituciones, como las órdenes religiosas y colegios profesionales, imponían limitaciones a este grupo racial.

La relevancia económica que llegaron a alcanzar los pardos junto con las perennes necesidades de ingresos de la Real Hacienda fueron factores que hicieron que la Corona dictaminase la Real Cédula de "Gracias al sacar", originada en 1773 pero dictaminada en 1795 , en la que se regulaba la posibilidad de "blanquear" la sangre de los pardos previo pago de un canon estipulado. La aplicación de esta ley provocó un profundo malestar entre los criollos, pues rompía el inestable y ya de por sí delicado equilibrio entre los grupos sociales constituyentes de la colonia. Ante esta muestra, considerada de torpeza por parte de los legisladores indianos, el Cabildo de Caracas alzó su voz de protesta en un informe de 28 de noviembre de 1796, aludiendo al hecho de que, con la aplicación de la ley, se rompía la estructura socio-racial establecida desde la conquista:

[...] es espantoso a los vecinos y naturales de América, porque sólo ellos conocen, desde que nacen o por el transcurso de muchos años de trato en ella, la inmensa distancia que separa a Blancos y Pardos; la distancia y superioridad de aquéllos, la bajeza y subordinación de éstos: como que nunca se atreverán a creer como posible la igualdad que les pronostica la Real Cédula, si no hubiera quien protegiéndoles para depresión y ultraje de los vecinos y naturales Blancos, los animase y fervorizase con la esperanza de una igualdad absoluta con oposición a los honores que hasta ahora han sido exclusivamente de los Blancos.21

Junto a esta desigualdad natural entre los distintos grupos, el Cabildo de Caracas esgrimía otro argumento muy en boga en la época; se trataba del "infame

21 José Félix Blanco y Ramón Azpurua (comps.), Documentos para historia de la vida pública del Libertador vol.I, Caracas, Eds. Presidencia de la República, 1975, p.268. 
origen" de pardos, zambos y mulatos. Pero, no obstante, había otro argumento de más peso que podía suponer la muerte del sistema esclavista; según el Cabildo de Caracas era imposible la equiparación de blancos y pardos porque el origen de los pardos no era otro que la esclavitud.

La Real Cédula equiparaba los derechos de los pardos y los blancos, rompiendo la situación colonial y creando una tendencia a la igualdad entre los dos grupos de suerte que, al tener los pardos su origen en los dos grupos de suerte que, al llegar a perder el espíritu de sumisión, produciéndose la desaparición del sistema esclavista por la pérdida del prestigio y la superioridad por parte de los blancos. Los mantuanos caraqueños, por tanto, dejan ver claramente el temor a los hombres de color y a la revolución social en la Capitanía. Las necesidades defensivas de la colonia habían derivado en la creación de batallones de milicias de pardos, con la misma estructura que los formados por hombres blancos; en estos cuerpos auxiliares del ejército, los hombres de color recibían instrucción militar. Esta decisión de incluir en los planes de defensa militar a los pardos tampoco era bien vista por los caraqueños, que desde la revolución de Haití observaban con recelo la evolución de este grupo étnico. Si conseguían además obtener puestos de gobierno, al adquirir condición de "blancos" por medio de la Cédula de "Gracia al sacar", la revolución sería inevitable según los caraqueños, pues provocarían la insurgencia general. El temor de los mantuanos a los pardos se hizo extensivo a las autoridades coloniales, que veían en esos grupos el mejor caldo de cultivo para la revolución; en el fondo se trataba de evitar la influencia de 450.000 pardos y negros libres, frente a los 187.000 blancos, que tampoco formaban un grupo homogéneo.

Creemos que, con esta Real Orden, la Corona pretendía evitar una situación tan tensa como la que podía derivarse de su aplicación. En este proceso revolucionario de Haití los pardos "affranchis" habían jugado un papel decisivo; en un principio, participaron junto a los republicanos que habían propuesto la equiparación de derechos, pero la oposición de los plantadores dejó sin efecto la orden. Posteriormente, radicalizaron sus posturas y se sumaron a la revolución de los esclavos, llegando a jugar así un papel decisivo en los acontecimientos. La Corona española pretendía colmar las aspiraciones de los pardos enriquecidos equiparándoles en derechos a los blancos, y de esta forma fortalecer su posición en la colonia, con ello intentaba evitar una radicalización de aquellos que hiciera 
peligrar el orden colonial. La oposición mantuana a la reordenación social es una muestra más de la resistencia de los criollos a las reformas del sistema colonial propuesto por los Borbones, que pretendía un mayor control sobre las colonias.

La propaganda francesa estaba teniendo buena acogida, según los informes de la Capitanía general y se temía que los pardos pudieran encontrar en la Revolución Francesa el marco teórico para formular sus reivindicaciones sociales; pero los "progresos" revolucionarios, al igual que en el caso de la propaganda, quedaron limitados a unos comentarios entre algunos pardos libres o esclavos. Sin embargo, tanto los mantuanos como el Capitán General veían en estas acciones (que, por otra parte, habría que confirmar si fueron ciertas) el planteamiento de una situación como la de Haití.

No podemos negar la posibilidad de que existieran elementos favorables a la Revolución Francesa, tanto entre los criollos como entre los pardos; pero parece que todo el revuelo levantado en la capitanía de Venezuela con motivo de la revolución de Saint-Domingue obedeció más a l os temores de los blancos y a la necesidad de buscar apoyo de la Corona para lograr imponer su modelo de sociedad que a una expansión del hecho revolucionario en sí. No obstante las revueltas de esclavos y la resistencia a la dependencia por parte de los libres fueron una buena excusa para que los blancos ejercieran la coacción. La presentación de la queja por el Cabildo de Caracas obedecía al interés que tenía la oligarquía capitalina de figurar como los verdaderos representantes de la Capitanía imponiéndose a los grupos de poder el resto de la Provincia.

\section{La propaganda revolucionaria}

$\mathrm{Al}$ margen de las tensas situaciones provocadas por la guerra de la Convención contra Francia y del espíritu de proselitismo que pudieran tener los prisioneros, agentes y simpatizantes del nuevo sistema francés, los representantes de la Corona de España en América tuvieron que enfrentarse a nuevas situaciones problemáticas, originadas por la propaganda revolucionaria francesa.

La propaganda francesa impresa no constituyó, en ningún caso, un problema tan grave como el planteado por los agentes o los prisioneros de esa nacionalidad. Estos folletos y opúsculos iban dirigidos a un segmento de la 
población que podía ser controlado más fácilmente que los posibles receptores de propaganda oral. Sólo un pequeño grupo de pobladores que sabían leer podía ser susceptible de recibir las informaciones de Francia; este sector de población estaría compuesto por profesionales liberales, junto a medianos y grandes propietarios. Descartamos como receptores de la propaganda revolucionaria a los grandes propietarios, exclusión que no prejuzga que este grupo no pretendiese un cambio en la dirección política de la colonia o que buscase la independencia; en este caso, por la propia estructura productiva de la Venezuela colonial basada en la explotación de la mano de obra esclava controlada por este pequeño grupo de propietarios, no querían estos, ni quisieron en el momento de la independencia cambiar las estructuras sociales de la Capitanía. Si la Revolución Francesa declaraba la igualdad de los hombres y la Convención abolía la esclavitud, se nos hace difícil pensar que los mantuanos pretendiesen establecer un orden social inspirado en ella, lo que hubiera significado su muerte como grupo de influencia. Si se ponía en práctica el sistema propuesto por algunos folletos franceses, debía acabarse con la esclavitud; es por esto por lo que consideramos que el grupo de grandes propietarios debe ser excluido de los posibles receptores de la propaganda francesa. Recordemos también que, al margen de este argumento, ya hemos visto en las páginas precedentes el miedo que producía a los mantuanos el cambio social, y como cerraron filas en torno a los grupos más conservadores de la administración colonial para afrontar el problema.

El grupo de los grandes propietarios, "[...] incluyendo criollos y peninsulares, estaba formado por 658 familias nucleares que totalizaban 4.848 personas, cifra esta última equivalente a menos del $0,50 \%$ de la población venezolana a fines de la colonia"; si bien eran escasos en cuanto al número y porcentaje dentro del total de población de la Capitanía, detentaban el control político en las ciudades, y su influencia se extendía hasta el propio gobierno colonial.

Los folletos revolucionarios que causaron mayor inquietud en el ámbito colonial. En primer lugar nos ocuparemos de la obra "Derechos del hombre y del Ciudadano, con varias máximas republicanas y un discurso preliminar dirigido a los americanos"; las primeras noticias de este folleto proceden de la Audiencia de Caracas, que, reunida en sesión plenaria del 11de diciembre de 1797, prohibió la circulación y difusión del libro de mismo título. Según la Real Audiencia, una de las causas de la sublevación de Gual y España fue la propaganda francesa. 
La aparición y difusión de esta obra se debió principalmente como ya hemos indicado a Gual, traductor y autor del discurso preliminar; su impresión se hizo en Madrid, en 1797, y la arribada a Tierra Firme se produjo a través de las Antillas francesas o de Trinidad, en posesión inglesa. Los aspectos que nos interesa resaltar son: en primer lugar, la autoría de la obra; ya hemos apuntado anteriormente que este libro no debía de ser confundido con el folleto aparecido en Santa Fe el año 1793, que corresponde a la Declaración de Derechos francesa de 1789, y que había sido condenado y perseguido por el Tribunal del Santo Oficio ya en ese mismo año, antes de que se conociera en América; como ya hemos apuntado, este folleto está fechado en 1797, y fue difundido por los conspiradores del grupo de Gual, Picornell y España. En segundo lugar, la presencia francesa, que sigue siendo constante pese a que se había firmado la paz entre España y Francia tras la guerra de la Convención, pues existía además un tratado de alianza entre los dos países: sin embargo, la presencia de propaganda francesa en estos años es, si cabe, más importante, que durante el conflicto.

La actuación de las autoridades españolas frente a la propaganda francesa se había relajado considerablemente con respecto a los años anteriores. Esta situación permitió un mayor desarrollo de los círculos republicanos, que, si durante el periodo de la Convención fueron conformados por los extranjeros y algunos mulatos, durante los años siguientes se incluyeron militares y algunos profesionales liberales que recibieron así el mensaje revolucionario. Otra diferencia constatable entre ambos periodos es la que se refiere al mensaje propagandístico y su procedencia; en el caso de la traducción de "Los derechos del hombre y del ciudadano" de 1797, la propuesta política es radical, y el emisor, pese a ser originariamente francés, se sitúa en la metrópoli; no parece que Francia tuviera especial interés en hacer fracasar al colonialismo español. Durante la guerra de la Convención, la propaganda de origen francés recibida en Venezuela procedía directamente de Francia o de sus colonias en el Caribe. En los años siguientes, la propaganda procedería de España, y sería introducida en América por republicanos españoles exiliados. La actitud de Francia es en estos momentos menos proselitista, por lo que la inestabilidad política en las colonias españolas contará con el apoyo de los ingleses, especialmente de su gobernador en Trinidad, Picton.

Las propuestas políticas de esta segunda fase de propaganda francesa, que, insistimos, llega desde España o bien vía Trinidad, y no desde Francia, son más 
radicales en cuanto al tema de los derechos del hombre; proponen aplicar la constitución francesa al caso de las colonias españolas. El folleto tiene un preámbulo "dirigido a los americanos" en el que se censuran los injustos procedimientos del gobierno español:

[...] y de los horrores de su despotismo nos resolveremos sin duda alguna a proscribirle enteramente: a abolir sus bárbaras leyes, la desigualdad, la esclavitud, la miseria y el envilecimiento general; trataremos de sustituir la luz a las tinieblas, el orden a la confusión, el imperio de una ley razonable y justa a la fuerza arbitraria y desmedida, [...] en una palabra, trataremos de buscar los medios más eficaces para restituir al pueblo su soberanía, a la América entera los imponderables bienes de un gobierno paternal. ${ }^{22}$

La idea fundamental de todo el discurso preliminar gira en torno a "la luz", de la misma forma que durante el periodo ilustrado "luz y tinieblas" representaban alegóricamente toda una serie de oposiciones político-sociales. La herencia ideológica de la revolución republicana que pretendían los exiliados españoles en América está, al menos formalmente, extraída del ideario ilustrado. Sí es cierto que se trataba de "devolver la soberanía popular", pero esta soberanía debía crear "gobiernos paternales" que se ocuparan, y desarrollaran ideas con tal fin, del bienestar del pueblo. Los ilustrados españoles, si bien es cierto que pretendían mejorar la calidad de vida de los súbditos, cuando se plantearon el problema americano sólo supieron ver una solución: aumentar la presión fiscal para mejorar el Erario Público; y en esta línea desarrollaron todo el programa de reformas, que se limitó, prácticamente a mejorar la Hacienda. Por ello creemos que, efectivamente, la Ilustración llegó a América con retraso. No se puede afirmar que las medidas reformistas desarrolladas y aplicadas durante los reinados de Carlos III y Carlos IV fueran dirigidas a mejorar la calidad de vida de los súbditos americanos. Será, sin embargo, con la presencia de los exiliados españoles cuando puedan apreciarse cambios cualitativos en las demandas, si bien es cierto que ninguno de estos proyectos revolucionarios triunfó.

Creemos que la influencia de los filósofos franceses había sido escasa en las

22 Pedro Grases, Preindependencia y emancipación: protagonistas y testimonios, Madrid, Seix Barral, 1981, p.189. 
colonias, al menos la de los que estudiaban las situaciones políticas del pasado para intentar mejorar la acción de gobierno en su época; pero no descartamos que la influencia de los políticos hubiera sido efectiva, como en el caso del discurso preliminar de Gual. Vemos que hay una influencia directa de la Ilustración en la forma de las críticas que se hacen al gobierno monárquico justificando su derrocamiento, que coinciden con las que hacen a los regímenes anteriores: corrupción en la administración, despotismo del gobierno, y excesivo poder de los funcionarios, razones que evidenciaban la necesidad de cambios en la administración. Por otra parte, existe una idea fundamental que se repite durante el periodo ilustrado: el progreso; todas las medidas desarrolladas por los revolucionarios iban encaminadas a conseguir el progreso de los pueblos, entendiéndose este bienes tal como su incorporación al sistema liberal capitalista.

El progreso de los pueblos se alcanzaría mediante la productividad. De la misma forma que los ilustrados españoles unos años antes, los revolucionarios tratan de devolver la dignidad a los pueblos:

\begin{abstract}
Así, hacer de un vasallo, o de un esclavo, que es lo mismo, un republicano, es formar un hombre nuevo, es volver todo al contrario de lo que era, [...] es necesario que la revolución sea al mismo tiempo, moral y material, [...] es necesario, además, poner el mayor estudio en regenerar las costumbres para volver a todo ciudadano el conocimiento de su dignidad. ${ }^{23}$
\end{abstract}

La Revolución, que en este caso es sinónimo de Ilustración, devolverá la dignidad y creara un ciudadano nuevo y feliz, alimentado e inspirado por su espíritu. Pese a la insistencia, tanto en las palabras iniciales como en las máximas republicanas y el articulado de los derechos del hombre y del ciudadano, en el aspecto de la salvaguarda de la propiedad privada, reconociéndose que el derecho a la propiedad es inalienable, la oligarquía se sintió poco atraída por un sistema que propugnaba la libertad de los esclavos y la equiparación de derechos entre todos los hombres.

Para hacer frente a la propaganda revolucionaria que llegaba de las colonias extranjeras, pero en especial para combatir la influencia del libro Los derechos del hombre y del ciudadano, la Audiencia de Caracas dictaminó una serie de

23 P. Grases, Preindependencia y emancipación, pp.193-194. 
medidas, entre las que se encontraba una recompensa para todos aquellos que denunciasen la existencia de tal propaganda. Se ordenó, así mismo, que quien arrancase la copia del acuerdo de la Audiencia del lugar donde estuviera expuesta fuese castigado con doscientos azotes o cuatro años de cárcel según las circunstancias. Para atajar el influjo del libro, que tuvo eco considerable en la Capitanía General, se comunicó al obispo la resolución de la Junta así como el peligro que suponía esa obra, por lo que se le rogaba que tanto el clero regular como el secular trabajasen de acuerdo con las justicias locales para evitar el contagio revolucionario.

Los republicanos afirman la existencia de un ser supremo, pero casi natural; la función de Dios es la creación de todos los hombres libres e iguales, así como sería también el encargado de premiar la virtud; el servicio a Dios pasa por el cumplimiento y respeto de los del hombre. Por otra parte, al crear un hombre nuevo los republicanos serían la representación de la virtud, frente a los vicios que eran constituyentes del despotismo.

Un segundo folleto que preocupó a las autoridades españolas, si bien su difusión y trascendencia fue mucho más limitada que la obra anterior, fue "El extracto del manifiesto que la Convención de París hace a todas las naciones". Las primeras noticias que tenemos del folleto datan de abril de 1794, fecha en que llegó a manos de un hombre del batallón de pardos de Caracas que lo entregó en la Secretaría del Capitán General. Cabe señalar que desde los primeros momentos de introducción de propaganda, uno de los sectores sociales que más recibieron el "bombardeo" fue el militar. En casi todas las actuaciones contrarrevolucionarias aparecen oficiales o suboficiales de los distintos batallones del ejército colonial; tal sería el caso de la sublevación de Gual, Picornell, España, o en los intentos de sublevación de Cartagena. Si las denuncias provienen, en estos casos de militares es porque posiblemente, los revolucionarios querrían contar con grupos armados organizados; no es tampoco casual que fuesen los batallones de pardos uno de los objetivos de los revolucionarios, ya que estaban obligados por todos los deberes que implicaba la ciudadanía, pero por su calidad de pardos, no gozaban de los derechos que otorgaba esa condición. Esta situación peculiar les convertía en posibles portadores de las ideas revolucionarias. De hecho fueron los pardos los que más controles debieron soportar a causa del miedo que inspiraban tanto a los criollos como a las autoridades coloniales. Otro de los grupos proclives a la 
revolución era el formado por los profesionales: así, encontramos encausados por la traducción de "Manifiesto..." a dos boticarios, un pasante de la botica y un capitán de la marina mercante; pero las averiguaciones que se hicieron para lograr encontrar al traductor no dieron resultados positivos. El manifiesto es un panfleto en el que se exculpa a los franceses y se devuelven las responsabilidades a los reyes: “¿De qué nos acusan?, de sus mismos crímenes. El manifiesto rechaza todas las acusaciones que se hacen en Europa sobre la República francesa y justifica la exportación de la Revolución a Europa para liberar a los pueblos del dominio de los déspotas". Otra de las características de todas las obras y opúsculos revolucionarios que llegan a América es el interés que ponen en desdramatizar la irreligiosidad de la Revolución. Ya vimos como en el caso anterior se trataba de identificar republicanismo y amor al Ser Supremo; el verdadero cristiano es el republicano, y en el Extracto del Manifiesto se defienden acusando a los sistemas monárquicos:

\begin{abstract}
Dicen que hemos declarado la guerra al mismo Dios. iQué edificante es la piedad de los tiranos! Muy agradables deben ser para el cielo las virtudes de sus cortes. ¿Cúal es este Dios del que hablan? ¿conocen otro que la soberbia, la corrupcición y toda suerte de vicios? Ellos mismos se llaman "las imágenes de la Divinidad", naturalmente para inducir al mundo a que abandonen sus altares. Aseguran que su autoridad es obra de Aquél. No; Dios ha creado a los tigres, pero los reyes son la obra exquisita de la corrupción humana. ${ }^{24}$
\end{abstract}

La rapidez con que se atajó la difusión del folleto revolucionario y el escaso eco que por ello tuvo hizo que no causara excesivo recelo en las autoridades de la Capitanía. En los autos que se siguieron para descubrir al traductor y difusor de la obra no se obtuvieron resultados positivos. Se interrogó por dos veces a cada uno de los implicados en la traducción, pero no se consiguió averiguarquién había sido el responsable de la introducción de la obra ni el camino que ésta había recorrido hasta llegar a Caracas. Una de las cuestiones más preocupantes para las autoridades coloniales era el descubrimiento no tan sólo de los folletos y obras francesas sino también el medio de arribada y los canales de distribución que seguían ya territorio americano. Se sabía que, durante la guerra de la Convención contra Francia (1793-95), los folletos procedían de las colonias francesas del

24 AGI, Sec. Estado, leg.65. Extracto del manifiesto que la Convención nacional de París hace a todas las naciones, Caracas 22 de mayo de 1794. 
Caribe; pero con el cambio de mando de España (1796) y la ocupación de Trinidad por los ingleses (febrero de 1797), el objetivo de la persecución española fueron éstos. Durante la guerra de la Convención, se apoderó de los españoles un delirio anti francés, en muchos casos sin otra justificación que el mero hecho de estar en guerra contra este país. La situación de tensión desatada en las colonias francesas, especialmente en Saint-Domingue, hacía, prácticamente imposible la protección francesa a los revolucionarios españoles o americanos. En estas circunstancias apareció el "Manifiesto de la Convención de París"; y quizás por la celosa vigilancia de las Justicias locales, o por la captación de la realidad por parte del Capitán General, quién sabía que el peligro se encontraba en la difusión oral de los contenidos de las obras y no en los escritos en sí, se puso en definitiva poco interés en aclarar la procedencia del folleto de manera que, una vez se supo que no había trascendido más que a las personas interrogadas se dio la cuestión por zanjada.

Otro de los folletos introducidos en Venezuela durante los años de la Alianza franco-española fue el titulado "Ynstrucción que deve servir de regla al agente Ynterino francés destinado en la parte española de Santo Domingo". 25 Como consecuencia de la paz de Basilea se puso fin a las hostilidades entre España y Francia en 1795, España tuvo que ceder a Francia la parte oriental de Santo Domingo. Los franceses necesitaban mantener las fronteras de la isla seguras, sin injerencias en los problemas internos de su zona, por lo que forzaron esa entrega por parte de España, país que no había sido ajeno a los problemas franceses. Como era habitual en las cesiones territoriales, el país ocupante daba instrucciones al gobernador interino que se encargaría de los asuntos de gobierno durante el tiempo que durase el abandono definitivo de la colonia por parte de la antigua metrópoli. Como era normal, los colonos se incorporaban a la nueva metrópoli como súbditos de pleno derecho, y por regla general solían gozar de un estatuto especial para que la incorporación no fuese tan traumática. La nueva potencia ocupante reconocía los títulos de propiedad de los colonos, o indemnizaba por las posibles expropiaciones que pudieran derivarse de la ocupación. El problema planteado por la toma de posesión de Santo Domingo por Francia era de difícil solución pues suponía una contradicción. Se trataba de respetar dos derechos consagrados en la constitución francesa, el derecho a la propiedad y el derecho a la libertad. La

25 AGI, Sec. Estado, leg.58. 
Convención de París había declarado en su constitución que "[...] ninguno puede ser privado de la menor porción de su propiedad sin su consentimiento, si no es en el caso de que una necesidad pública legalmente probada lo exija, y bajo la condición de una justa y anticipada indemnización". Pero igualmente la propia constitución declaraba en su artículo anterior que "[...] todo hombre puede entrar al servicio de otro, pero no puede venderse, ni ser vendido. Su persona es una propiedad inajenable. La ley no conoce esclavitud: entre un hombre trabaja y aquel que le emplea no puede existir mas que una obligación mutua de cuidado y de reconocimiento". ${ }^{26}$

Para resolver el problema, que los franceses sabían se les plantearía en términos de respeto a la propiedad privada, acordaron que el derecho a la libertad era anterior al de la propiedad, de suerte que no indemnizarían a los propietarios de esclavos, que deberían contentarse con esta disposición: "[...] que sus esclavos libres ya no abusarán de su libertad sino que les serán al contrario siempre adictos, y que no se separarán jamás de su lado como hijos reconocidos [...] Mas cuando la libertad de los esclavos fuese una pérdida real para sus dueños, quedaría esta suficientemente compensada con la garantía que la constitución les ofrece de la propiedad del territorio".27

Lo que verdaderamente preocupaba al Capitán General de Caracas no eran las revueltas que se produjeron en Santo Domingo ni en Haití, sino las repercusiones que pudiera tener la "ynstrucción de Gobierno entre las gentes sencillas, especialmente en los esclavos que en sola esta provincia pasaran de cien mil”. ${ }^{28}$

Para evitar la circulación de la Instrucción en la Capitanía General, la Junta de Gobierno de Caracas ordenó a todos los justicias y gobernadores que se encargasen de recoger todas las copias de que tuviesen noticia y las pagasen a los ministros de la Audiencia, para iniciar las acciones de gobierno pertinentes. Todos los informes de las autoridades coloniales tanto a nivel local como regional enviados por vía reglamentaria hacen mención del poderoso influjo que la

\footnotetext{
26 Derechos del hombre y del ciudadano, artículo XVIII, citado por P. Grases, Preindependencia y emancipación, p.206.

27 AGI, Sec. Estado, leg.58. Ynstrucción que deve servir de regla al agente Ynterino francés destinado en la parte española de Santo Domingo. Caracas2 de junio de 1796.

28 AGI, Sec. Estado, leg.58. Acuerdo de la Junta de Caracas 19 de mayo de 1796.
} 
Revolución Francesa podía tener entre los esclavos; pareciera que estos procesaran las escasas informaciones que recibían y formularan, partiendo de ellas, la teoría política del estado. Solo en el informe que la junta de la Audiencia de Caracas hizo sobre el peligro que podía representar la divulgación de "La Ynstrucción [...] entre los esclavos se observa que este papel comprehende varias expresiones capaces de causar perjudiciales imprecaciones en la gente sencilla [...] si como es de temer corriere semejante papel, y llegaren ellos (los esclavos) a entender la cláusula en que hablando con el insinuado Agente dice [...] aniquila el derecho horrible de la esclavitud". ${ }^{29}$

Este era el verdadero problema, la lucha por la libertad de los esclavos, que podrían ver reforzadas sus aspiraciones por el hecho de que Francia hubiera decretado la liberación en sus colonias, incluso sobre las que no ejercía dominio sino de derecho como era el caso de la parte española de Santo Domingo. Pero en cualquier caso, no creemos que los esclavos necesitaran alicientes externos para plantearse intentar conseguir salir de su situación.

Veremos por último un aspecto poco conocido de la propaganda francesa en América, como es la postura del episcopado constitucionalista francés con respecto a las críticas que desde el episcopado español se hacían a la Revolución acusándola de atea. Si desde un punto de vista filosófico y político la Revolución Francesa fue heredera directa de la Ilustración, también lo fue en el aspecto religioso; y si en política las posturas evolucionaron del Despotismo Ilustrado a la República, en religión pasaron de un Deísmo natural, casi panteísta, a la ruptura con Roma y al ataque a la Iglesia institucional. Como acción más destacada derivada de esta ruptura cabría señalar el exilio al que fue sometido el Papa en 1797 hecho que provocó el cierre de filas en torno al Pontífice y la creación de un sentimiento de persecución entre los católicos.

El folleto que apareció en Caracas llevaba por título "Observaciones sobre las reservas de la Iglesia de España", ${ }^{30}$ y sus autores eran los obispos de Dax,

29 AGI, Sec. Estado, leg.58. Ynstrucción que deve servir de regla al agente Ynterino francés destinado en la parte española de Santo Domingo. Caracas2 de junio de 1796.

30 AGI, Sec. Estado, leg.71. Observaciones sobre las reserva de la iglesia de España por los obispos de Dax, Amiens, Blois y Cayenne, reunidos en Paris, Paris, Imp. Librería Christiana, 1799, p.11. 
Amiens, Blois y Cayenne. Su origen está en una reunión que estos obispos mantuvieron en París, y su publicación en lengua castellana en la capital francesa data del año 1799. El folleto fue escrito después de que las tropas francesas deportaran a Pío VI, en 1797 y, como consecuencia, se desencadenase una cruzada antirrevolucionaria. El Santo exilio no debió estar exento de cierto revanchismo por parte de los revolucionarios, que de esta forma contestaban al cúmulo de excomuniones de que habían sido objeto por parte del representante de Dios en la tierra. La acusación de que fueron objeto los artífices y seguidores de la Revolución fue de ateísmo; pero en el fondo subyacía, la cuestión de la ruptura del episcopado francés con Roma, esto es, la aceptación y creación de una Iglesia nacional francesa. Y este punto resulta ser el caballo de batalla de todo el opúsculo, pues la idea fundamental desarrollada a lo largo de todo él es el intento desesperado de convencer a los obispos españoles de que la iglesia francesa se había limitado a retomar los poderes "[...] contra las impías usurpaciones de la curia romana, y del tribunal de la Inquisición”, y por lo tanto no plantearon en ningún momento ninguna innovación en el seno de la iglesia, pues los innovadores no eran sino los seguidores del Vaticano. La iglesia constitucional francesa mantenía, como en todos los casos de ruptura con Roma, que su propuesta eclesial era la auténticamente heredera de la Iglesia primitiva. Las reserva y mandatos eran derechos económicos que se atribuía al Pontífice para frenar el poder de las iglesias locales, y por lo tanto son contrarias a la tradición canonista de la Iglesia; tuvieron su origen en el siglo XII, es decir seis siglos antes de la recuperación del poder por parte de los obispos. Según los obispos franceses, las reservas "[...] han continuado siendo para la corte de Roma una mina de oro que no ha cesado de beneficiar". ${ }^{31}$ Para los obispos constitucionalistas, las consecuencias inmediatas de estas reservas fueron la creación del tribunal de la Inquisición, que consolidaba el poder temporal del Papado, y el surgimiento de la arbitrariedad del romano pontífice, que mediante el control económico de las iglesias y el Santo Oficio recortaba los poderes de los obispos y sembraba el terror entre los fieles. Finalmente, el episcopado francés celebra la destrucción de "la corte de Roma” (que no debía ser confundida con la Santa Sede), hecho que significaba el fin del mantenimiento del boato del Papado. Los obispos no se oponían a la existencia de la Iglesia como institución espiritual que pudiera dirigir y velar por la pureza de la fe entre los católicos de todo el mundo; dicho de otra forma, son partidarios del mantenimiento de la Santa Sede, pero si se oponían a la

31 AGI, Sec. Estado, leg.71. Observaciones sobre las reserva de la iglesia de España, p.7. 
existencia y perduración del Estado Vaticano, que no era sino un claro signo de poder político y muestra palpable de la existencia de simonía en las altas esferas eclesiásticas.

\section{Bibliografía}

Archivo General de Indias (AGI) Sección Estado.

Blanco, José Félix y Azpurua, Ramón (comps.), Documentos para historia de la vida pública del Libertador vol.I, Caracas, Eds. Presidencia de la República, 1975.

Observaciones sobre las reserva de la iglesia de España por los obispos de Dax, Amiens, Blois y Cayenne, reunidos en Paris, Paris, Imp. Librería Christiana, 1799.

Callahan, William, "La propaganda, la sedición y la Revolución Francesa en la Capitanía General de Venezuela de 1789-1796", en Boletín Histórico n. ${ }^{\circ} 14$, Caracas, Fundación Boulton, 1967.

Debiens, Gabriel, "Les colons de Saint Domingue réfugiés a Cuba (1793-1815)", en Revista de Indias vol.XIII, n. ${ }^{\circ}$ 54, Sevilla, EEHA, 1953, pp.559-605, y Revista de Indias vol.XIV, n. ${ }^{\circ} 55^{-56}$, Sevilla, EEHA, 1954, pp.11-36.

Grases, Pedro, Preindependencia y emancipación: protagonistas y testimonios, Madrid, Seix Barral, 1981.

Santoiyant, Jules, La colonisation française pendant le Révolution (1789-1799), Paris, La Renaissance du Livre, 1930.

Sanz Tapia, Ángel, Los militares emigrados y los prisioneros franceses en Venezuela durante la guerra contra la revolución: (un aspecto fundamental de la época de la pre-emancipación), Caracas, Instituto Panamericano de Geografía e Historia, 1977.

Victoria Ojeda, Jorge, "La aventura imperial de España en la revolución haitiana. Impulso y dispersión de los negros auxiliares: el caso de San Fernando Aké, Yucatán”, en Secuencia n. ${ }^{\circ}$ 49, México, Instituto Mora, 2001, pp.70-85.

Victoria Ojeda, Jorge, "Tras los sueños de libertad: las tropas auxiliares de Jean François al fin de la guerra en Santo Domingo, 1793-1795”, en S. Broseta, C. Corona, M. Chust, et al (eds.), Las ciudades y la guerra, 1750-1898, Castellón, Universitat Jaume I, 2002, pp.509-524. 